\title{
Ion-neutral coupling in the high-latitude F-layer from incoherent scatter and Fabry-Perot interferometer measurements
}

\author{
K. Cierpka, M. J. Kosch, M. Rietveld, K. Schlegel, T. Hagfors \\ Max-Planck-Institut Aeronomie, 37191 Katlenburg-Lindau, Germany \\ Received: 14 January 2000 / Revised: 5 June 2000 / Accepted: 12 July 2000
}

\begin{abstract}
Since the auroral ionosphere provides an important energy sink for the magnetosphere, ionosphere-thermosphere coupling must be investigated when considering the energy budget of the ionospheremagnetosphere coupling. We present the first Scandinavian ground-based study of high-latitude F-region ion-neutral frictional heating where ion velocity and temperature are measured by the EISCAT incoherent scatter radar as well as neutral wind and temperature being measured simultaneously by a Fabry-Perot interferometer. A geomagnetically active period $\left(K_{p}=\right.$ $\left.7^{-}-5^{-}\right)$and quiet period $\left(K_{p}=0^{+}-0\right)$ were studied. Neglecting the neutral wind can result in errors of frictonal heating estimates of $60 \%$ or more in the F-layer. About $96 \%$ of the local ion temperature enhancement over the neutral temperature is accounted for by ion-neutral frictional heating.
\end{abstract}

Key words: Ionosphere (auroral ionosphere; ionosphere-atmosphere interactions)

\section{Introduction and theory}

One of the major sinks of magnetospheric energy, provided by the solar wind, is ionospheric Joule heating caused by the dissipation of Pedersen currents. Ionospheric ohmic heating is the second most important sink of magnetospheric energy after the ring current (Akasofu, 1981) and generally amounts to several times greater than that associated with auroral particle precipitation (e.g. Banks et al., 1981; Ahn et al., 1983). A major part of the energy released is deposited in the auroral zone (Kosch and Nielsen, 1995) and can be observed most easily as increased ion temperatures (Schlegel and Collis, 1999). It is important to study ionosphere-thermosphere coupling because ion-neutral

Correspondence to: M. J. Kosch

e-mail: Kosch@linmpi.mpg.de collisional friction is an important loss mechanism in the energy budget of ionosphere-magnetosphere coupling. During a major magnetic storm, Lu et al. (1998) showed that about $4 \%$ of the solar wind kinetic power $(11000 \mathrm{GW})$ was deposited in the magnetosphere $(460 \mathrm{GW})$, of which about $40 \%$ was dissipated in the ionosphere $(190 \mathrm{GW})$.

Incoherent scatter measurements and observations with a Fabry-Perot interferometer are an ideal combination for ionosphere-thermosphere coupling investigations. The former provides information about the ionised component, the latter about the neutral component of the atmosphere. Here we investigate ion-neutral frictional heating in the high-latitude F-region using ion velocity and temperature data obtained with the EISCAT incoherent scatter facility (Rishbeth and van Eyken, 1993), together with neutral winds and temperatures derived from Fabry-Perot interferometer measurements. EISCAT provides height profiles of electron density, electron and ion temperature, as well as the vector of ion velocity in the F-layer from tristatic measurements at $250 \mathrm{~km}$ altitude. The Max-PlanckInstitut für Aeronomie Fabry-Perot interferometer (Kosch et al., 1997a) is located near Skibotn $\left(69.35^{\circ} \mathrm{N}\right.$, $20.36^{\circ} \mathrm{E}$ ), Norway, about $50 \mathrm{~km}$ from the EISCAT Tromsø radar site. Observations are made at 630 and $557.7 \mathrm{~nm}$ wavelengths, corresponding to the upper $(\sim 250 \mathrm{~km})$ and lower $(\sim 115 \mathrm{~km})$ thermosphere, respectively (Kosch et al., 2000). Neutral winds and temperatures are derived from the Doppler shift and broadening, respectively, of the selected airglow/auroral emissions (Kosch et al., 1997b). By scanning the instrument to different azimuthal directions (north, south, east, west and vertical), neutral wind vectors with a temporal resolution of about $8-16 \mathrm{~min}$ are obtained, depending on the emission intensity.

Ion-neutral dynamics studies at high latitudes have been performed before from satellite measurements (e.g. Killeen et al., 1984, 1991; Killeen and Roble, 1988), with the Chatanika incoherent scatter radar and two groundbased interferometers (Sica et al., 1993) as well as with EISCAT and ground-based interferometers (e.g. Davis 
et al., 1995; Lilensten et al., 1992; Farmer et al., 1990; Winser et al., 1988; Rees et al., 1984). Most of the EISCAT related studies did not measure the neutral temperature directly. There has been only one attempt in the past to measure neutral winds and temperatures directly in conjunction with EISCAT, using a Michelson interferometer (Thuillier et al., 1990), but no further analysis other than simple comparison was done. Ours are the first such combined measurements, using a Fabry-Perot interferometer operating on a routine basis. The effects of the neutral winds on the ionospheric electric fields and the Joule heating rate have been investigated for a long time but from a rather theoretical point of view. Fujii et al. (1998) studied the neutral wind contribution to the ionospheric electrodynamics using EISCAT data but with neutral wind related electric fields derived from EISCAT observations only.

In order to calculate ion temperature enhancements over the neutral temperature, resulting from ion-neutral frictional heating, we apply the ion energy equation. The general form of the equation is given by e.g. Schunk (1977). For the assumptions of F-region heights, we use the following approximation made by St.-Maurice and Hanson (1982):

$3 k\left(T_{i}-T_{n}\right)=m_{n}|\mathbf{v}-\mathbf{u}|^{2}+\frac{m_{i}+m_{n}}{m_{i}} \frac{v_{i e}}{v_{i n}} 3 k\left(T_{e}-T_{i}\right)$

where $T_{i}, T_{e}, T_{n}$ are the ion, electron, and neutral temperatures, respectively, $\mathbf{v}$ the ion drift velocity, $\mathbf{u}$ the neutral wind vector, $m_{i}$ and $m_{n}$ are the ion and neutral masses, respectively, $v_{i n}$ and $v_{i e}$ are the ion-neutral and ion-electron collision frequencies, respectively, and $k$ is Boltzmann's constant. The difference between the ion and neutral temperature is determined by frictional heating, which occurs whenever there exists a relative velocity between the ion and neutral gas, and also by ion-electron heat exchange. Since the ion-electron collision frequency is much smaller than the ion-neutral collision frequency, the heat exchange term is often assumed to be negligible.

High electric fields cause a non-Maxwellian velocity distribution of the ions and the ion temperature becomes anisotropic (e.g. Gaimard et al., 1998). Since gyrotropic conditions in the F-region exist $\left(v_{\text {in }} \ll\right.$ ion cyclotron frequency), the ion thermal velocity distribution is symmetric with respect to the magnetic field, but the ion temperature parallel to the magnetic field $T_{i \|}$ is smaller than the "average" ion temperature $\left\langle T_{i}\right\rangle$ given by Eq. (1) (St.-Maurice and Schunk, 1977, 1979). Neglecting the ion-electron heat exchange term in Eq. (1), the parallel ion temperature can be described by the equation (e.g. St.-Maurice et al., 1999)

$T_{i \|}=T_{n}+\frac{m_{n}}{3 k}|\mathbf{v}-\mathbf{u}|^{2} 1.5 \beta_{\|}$

where $\beta_{\|}$is the ion temperature partition coefficient. McCrea et al. (1993) give an empirical expression for $\beta_{\|}$which depends on the momentum transfer collision frequencies for ion-neutral and Coulomb collisions. To a first approximation, $\beta$ is a constant depending on the collision model and the ion and neutral composition and remains less than or equal to $2 / 3$.
Both Eqs. (1) and (2) are employed to predict the F-layer ion temperature, using simultaneous EISCAT and FPI measurements for $\mathbf{v}, \mathbf{u}, T_{e}$ and $T_{n}$. The neutral mass $m_{n}$ is modelled by MSISE-90 (Hedin, 1991). Collision frequencies are calculated after Schunk and Walker (1973) and Kelley (1989) using MSISE-90 model values for the relevant number densities. The predicted $T_{i}$ are then compared to the values measured directly by EISCAT. Since the ion temperature recovered from the EISCAT CP-1 experiment is $T_{i \|}$ rather than $\left\langle T_{i}\right\rangle$, a suitable value for $\beta_{\|}$has to be assumed. Following St.-Maurice et al. (1999), for the oxygen-dominated atmosphere above $250 \mathrm{~km}, \beta_{\|}$should be between 0.18 and 0.25 . In the work presented here, calculations of $T_{i \|}$ are performed with $\beta_{\|}=0.67$, i.e. no correction for anisotropic ion temperature effects, which are compared with the results obtained with $\beta_{\|}=0.25$.

Since the ionospheric plasma in the high-latitude F-region is predominantly driven by electric fields, the frictional heating can also be described equally as Joule heating produced by the ohmic losses of the Pedersen current $\mathbf{j}_{p}=\sigma_{p} \mathbf{E}_{\text {eff }}$ with Pedersen conductivity $\sigma_{p}$ and effective electric field $\mathbf{E}_{\text {eff }}=-\mathbf{v} \times \mathbf{B}+\mathbf{u} \times \mathbf{B}$, taking into account the contribution of the neutral wind dynamo, where $\mathbf{B}$ is the Earth's magnetic field. The height-dependent Joule heating rate is given by $Q_{J, e f f}=\mathbf{j}_{p} \mathbf{E}_{\text {eff }}=\sigma_{p} \mathbf{E}_{\text {eff }}^{2}$. With the help of direct neutral wind measurements we can assess the significance of the neutral wind induced electric field on the local Joule or frictional heating rate at F-region heights.

\section{Results and discussion}

During the period of 17:30-23:00 UT on 9 and 10 November, 1998, a coordinated EISCAT-FPI experiment was performed. The EISCAT radar was operated with the Tromsø beam parallel to the magnetic field (CP-1 mode) with tristatic measurements of the ion drift at $250 \mathrm{~km}$ altitude. The FPI was operated at 630 and $557.7 \mathrm{~nm}$. In this study, only the F-region measurement at $630 \mathrm{~nm}$ is used as no EISCAT tristatic measurements were available in the lower thermosphere (corresponding to $557.7 \mathrm{~nm}$ ). The effective FPI observing height is inferred from the electron density peak height measured by EISCAT, based on the assumption that the maximum emission intensity will be near the height of peak ionisation (Herrero and Meriwether, 1980). The sampling time of the EISCAT measurements is 2 min with a height resolution of $22 \mathrm{~km}$ in the F-layer. A 2-point running average in time and a 3-point running average in altitude are used to smooth the data. The FPI measurement scan cycle is about $8 \mathrm{~min}$ ( $30 \mathrm{~s}$ integration) on the first night and $16 \mathrm{~min}$ (90 s integration) on the second night. The lower resolution on the second night results from longer integration times due to the lower emission intensity. The two nights of observation are characterised by large differences of geomagnetic activity. The first period was very disturbed with $K_{p}=7^{-}-5^{-}$, and electric fields up to $60 \mathrm{mV} / \mathrm{m}$, while the second period was very quiet with $K_{p}=0^{+}-0$, 
and electric fields below $20 \mathrm{mV} / \mathrm{m}$. This permits ionneutral coupling in the F-layer to be studied under very different geomagnetic conditions.

Simultaneous EISCAT and FPI measurements for 9 and 10 November, 1998, are shown in Figs. 1 and 2, respectively. The variation of magnetic activity is represented by the Polar Cap Index (Troshichev et al., 1988 ) in the last panel of each figure. In the top panel measurements of neutral (blue curve) and ion (red curve) temperatures are compared with the neutral temperatures (green curve) modelled with MSISE-90 (Hedin, 1991) and the predicted ion temperatures (black curve)
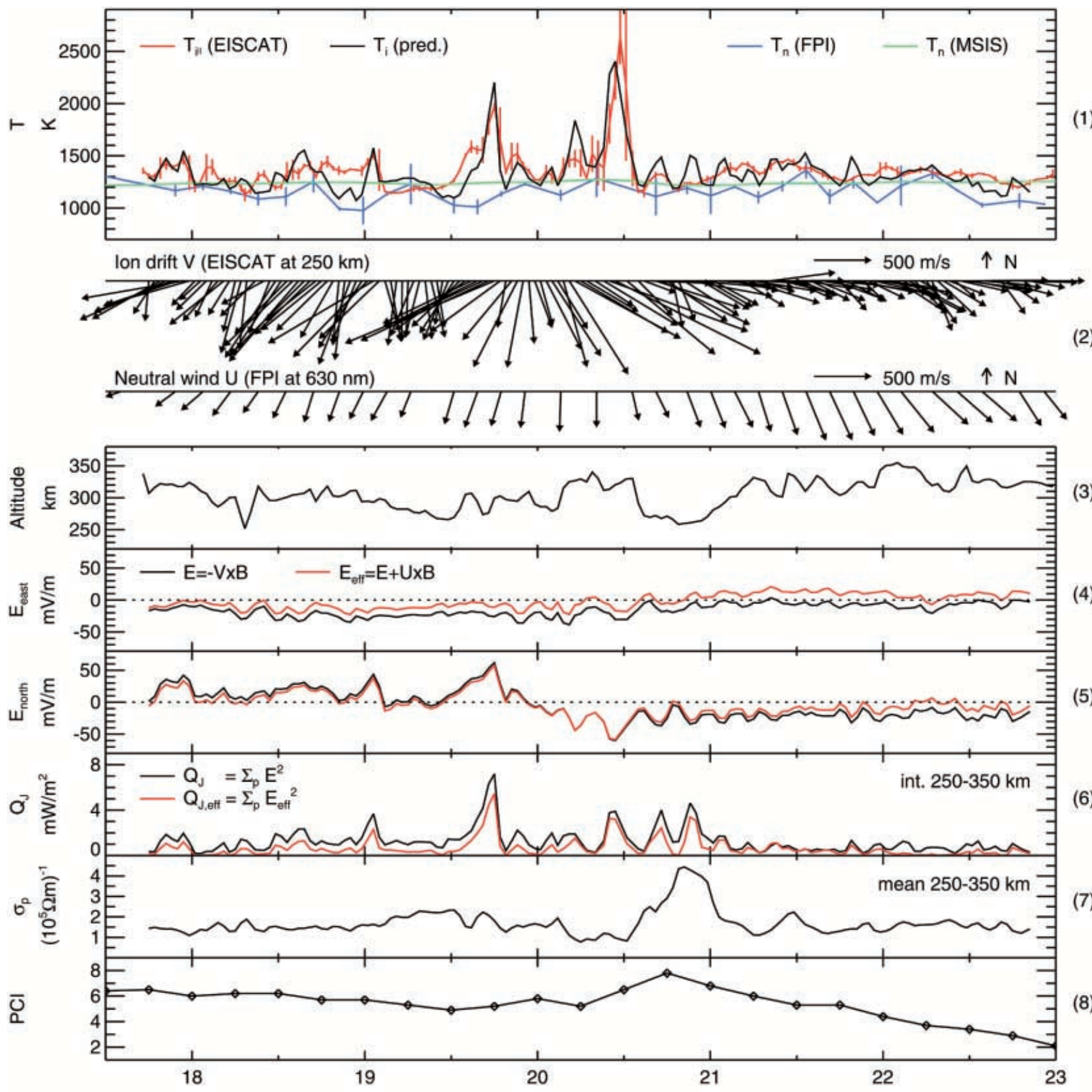

UT [h], 9 November 1998

Fig. 1. A composite plot of EISCAT and FPI observations versus universal time, in the F-region, for the geomagnetically active night of 9 November, $1998\left(K_{p}=7^{-}-5^{-}\right)$. From top to bottom: a comparison of ion (red curve) and neutral temperature (blue curve) measurements, neutral temperature modelled by MSISE-90 (green curve) and ion temperatures (black curve) predicted from the ion energy Eq. (1) (panel 1); measured ion drifts and neutral winds perpendicular to the magnetic field (panel 2); the assumed effective FPI observing height at $630 \mathrm{~nm}$ and altitude of ion temperature observations (panel 3); the electric field components (panels 4 and 5) and local Joule heating rate (integrated over the range $250-350 \mathrm{~km}$ ) (panel 6), calculated with (red curve) and without (black curve) the neutral wind contribution, respectively the Pedersen conductivity (averaged over the range 250$300 \mathrm{~km}$ ) (panel 7); and the Polar Cap index (panel 8) 

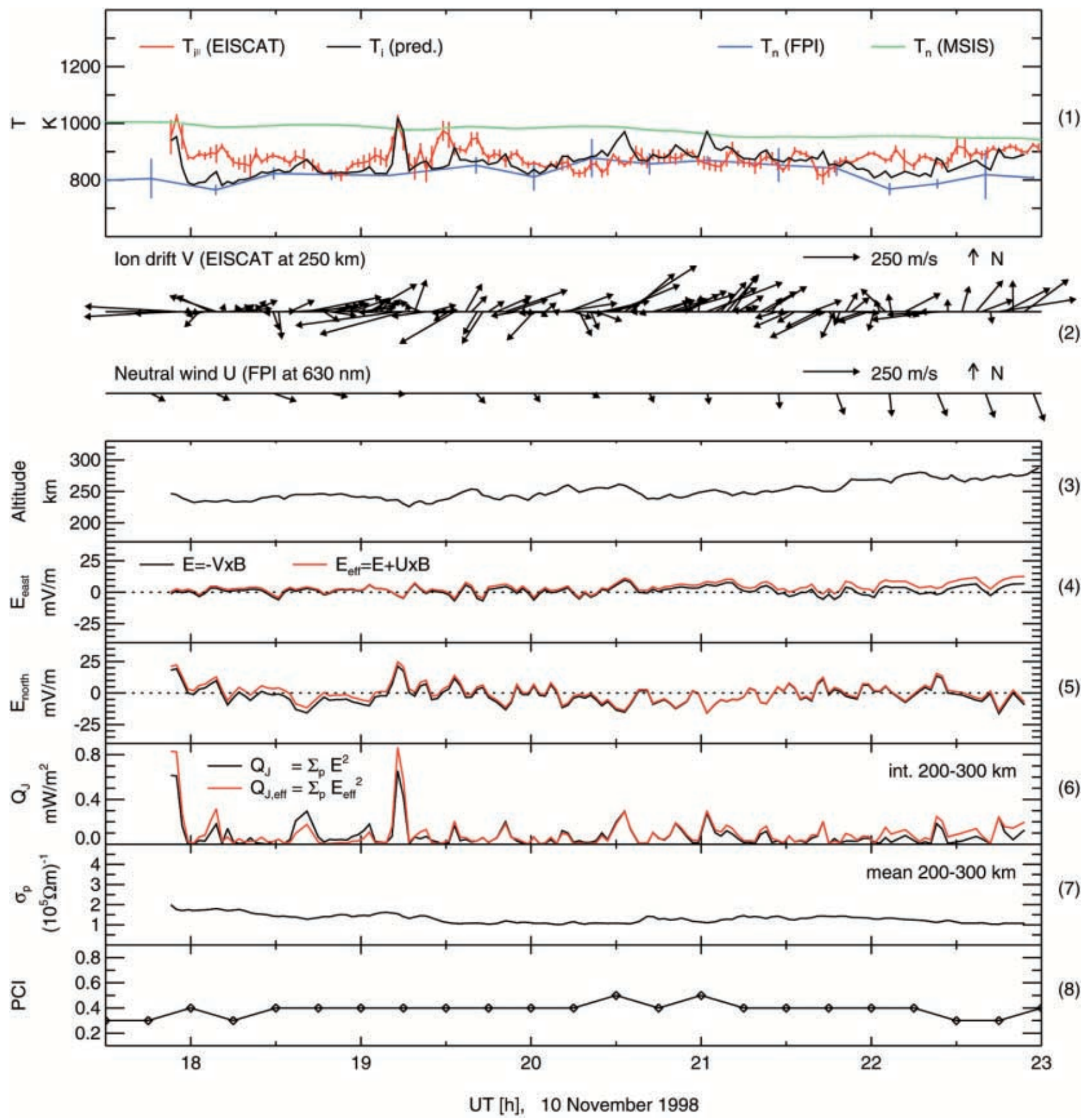

Fig. 2. Same as Fig. 1, but for the geomagnetically quiet night of 10 November, $1998\left(K_{p}=0^{+}-0\right)$. The height range for the integration of $Q_{J}$ and the mean of $\sigma_{p}$ has been changed because of the lower $h_{m} \mathrm{~F} 2$ height

using the ion energy equation 1 (i.e. no correction for anisotropic ion temperature effects). The EISCAT ion temperature, the MSISE-90 neutral temperature and the ion temperature prediction are given for the effective FPI observing height (panel 3). In order to calculate the ion temperature at the EISCAT data points, linear interpolation is used for the neutral FPI measurements. The vertical bars represent the error estimates. The error in $T_{i}$ is given by the standard deviation of the EISCAT raw data analysis. The error in $T_{n}$ is estimated by comparing independent fits to the first two FPI fringes.
Table 1 gives an estimate of the averaged absolute measurement uncertainties for the measured parameters.

The FPI neutral temperature is always lower than or equal to the EISCAT ion temperature: this is what is

Table 1. Averaged measurement errors (estimated)

\begin{tabular}{lll}
\hline & Temperature & Velocity \\
\hline EISCAT (ions) & $\pm 20 \mathrm{~K}$ & $\pm 60 \mathrm{~m} / \mathrm{s}$ \\
FPI (neutrals) & $\pm 100 \mathrm{~K}$ & $\pm 15 \mathrm{~m} / \mathrm{s}$ \\
\hline
\end{tabular}




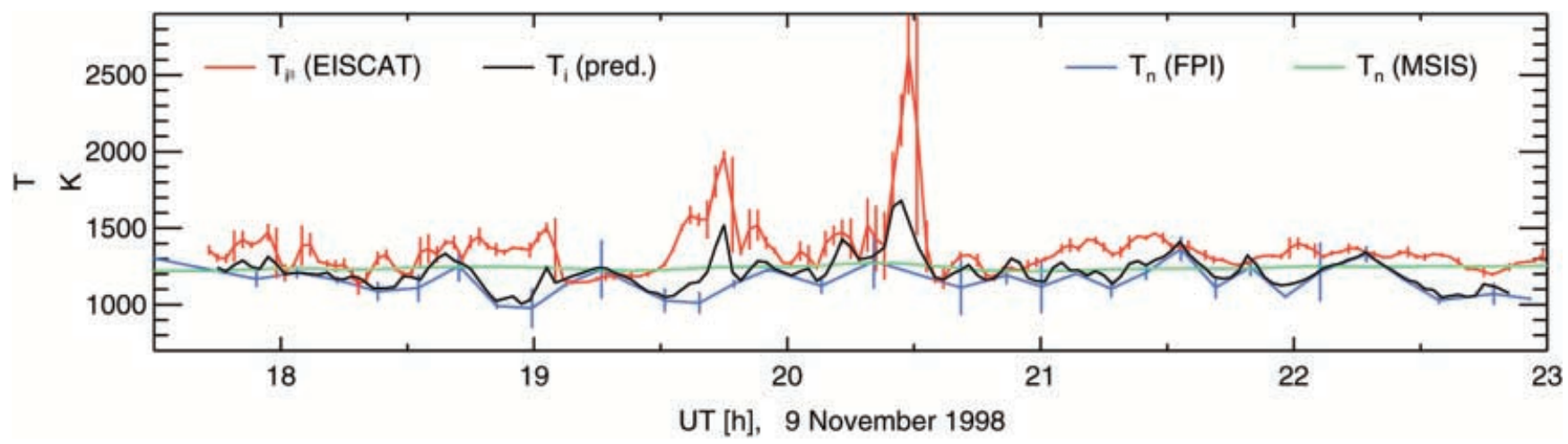

Fig. 3. Same as Fig. 1, panel 1, but with the parallel ion temperature (black curve) predicted from the ion energy Eq. (2) using $\beta_{\|}=0.25$

expected from the ion energy equation (Eq. 1). For the geomagnetically active period (Fig. 1) MSISE-90 makes a reasonable estimate of the neutral temperature, although deviations of up to $200 \mathrm{~K}$ (e.g. 19 UT) do occur when compared to the FPI measurements. The MSISE-90 model fails for the geomagnetically quiet period (Fig. 2), since the predicted neutral temperature level is on average approximately $100 \mathrm{~K}$ higher than the ion temperature. The reason for this is not clear, however, the problem must lie in the model as the neutral temperature can not be greater than the ion temperature (see Eq. 1). During the disturbed period (Fig. 1), large enhancements of $T_{i}$ over $T_{n}$, up to $1300 \mathrm{~K}$ (e.g. 20:30 UT), occur. These enhancements are well correlated with large differences between the measured ion drift and neutral wind (second panel of Fig. 1), indicating the dominance of frictional or Joule heating. For both observation periods there is good agreement between the measured ion temperature and their prediction from Eq. (1). At times, discrepancies of up to $200 \mathrm{~K}$ and $100 \mathrm{~K}$ do occur for the geomagnetically active (e.g. Fig. 1, 19:30 UT) and quiet (Fig. 2, 18 UT) periods, respectively. The calculation of ion temperature neglecting the ion-electron heat exchange term in Eq. (1) is not shown here. The same result is obtained using Eq. (2) with $\beta_{\|}=2 / 3$ (i.e. no correction for anisotropic ion temperature effects). However, the effect of ionelectron heat exchange is small in most cases and never exceeds $90 \mathrm{~K}$.

Figure 3 also shows a comparison of temperatures for 9 November, 1998, where the predicted parallel ion temperature is calculated using Eq. (2) with $\beta_{\|}=0.25$. For nearly the entire period investigated, the prediction is too low compared with the measurement. This strongly indicates that the ion temperature distribution in space is relatively isotropic. This implies a Maxwellian velocity distribution in this case even though the electric field exceeds $30 \mathrm{mV} / \mathrm{m}$ on average, peaking up to $60 \mathrm{mV} / \mathrm{m}$. Likewise, for the geomagnetically quiet day (10 November, 1998), anisotropic temperature effects do not occur in the data (not shown).

Figure 4 shows the distribution of the percentage difference between the measured and predicted ion temperature $\left(\beta_{\|}=2 / 3\right)$, separated for the magnetically active and quiet days. With a sampling time of $2 \mathrm{~min}$, the total number of sampled values are 149 and 137 for
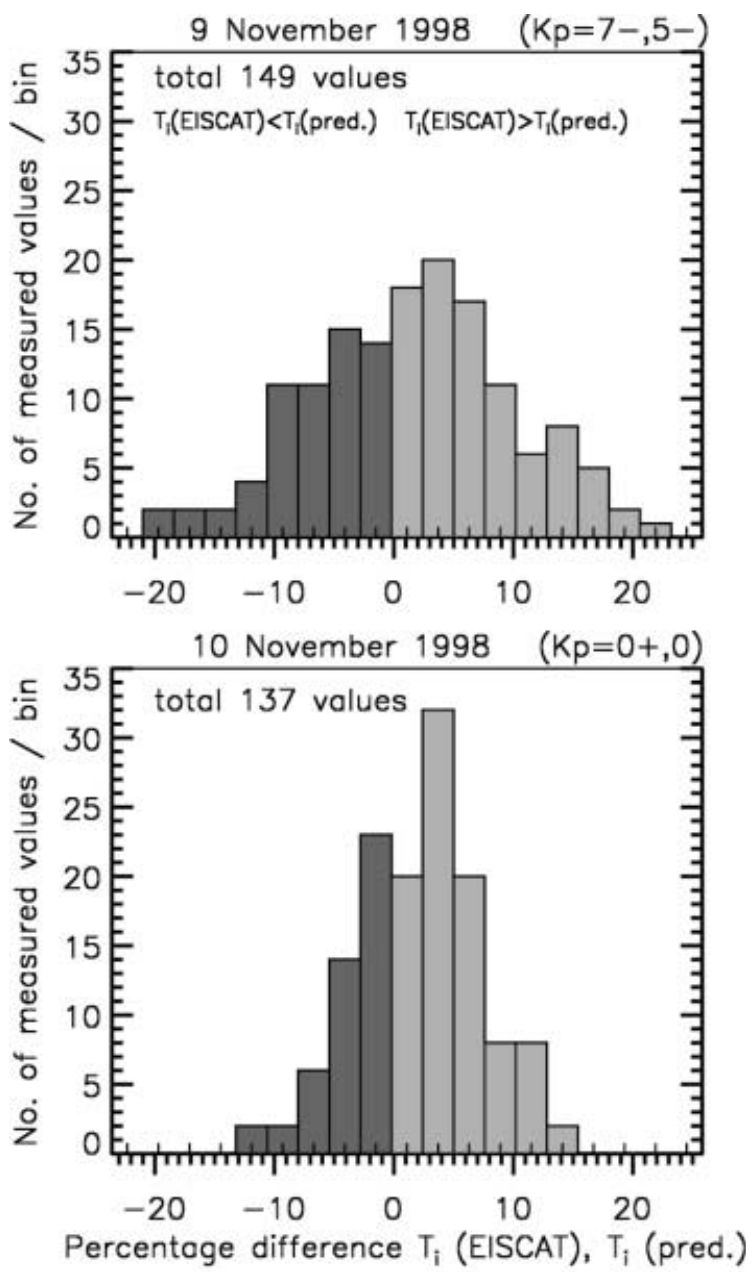

Fig. 4. Distributions of the percentage difference between measured and predicted ion temperatures for the magnetically active and quiet periods in the F-layer

the active and quiet period, respectively. The distribution for the quiet period (10 November) is somewhat narrower, but for both cases there are two common features despite the relatively low statistical sample. Firstly, the percentage differences are mostly less than $\pm 10 \%$ and therefore in the range of our expected measurement uncertainty (see Table 1). Secondly, the distribution maxima lie around $+4 \%$, indicating that 
the neglected heat sources in the simplified energy equation (Eq. 1), e.g. heat advection and heat conduction (see St.-Maurice and Hanson, 1982), contribute only a small fraction to the measured ion temperature. It is clear, however, that ion-neutral frictional heating is the most dominant F-region heating source, contributing about $96 \%$ of the ion temperature enhancement over the neutral temperature on average.

To compare the EISCAT ion temperature with the predicted one, which is based on the FPI measurement, it is necessary to determine the effective observing height of the FPI. The effective observing height is assumed to be one scale height below the electron density peak (H. Rishbeth, private communication) and is shown in the third panels of Figs. 1 and 2. This height is used in the data analysis, except for the ion drift which is fixed at $250 \mathrm{~km}$. Unfortunately, a more reliable method of observing height determination is not available. In contrast to our study, Sica et al. (1993) inferred the centroid height of the $630 \mathrm{~nm}$ emission, under the assumption that Eq. (1) gives an appropriate description of the ion energy balance. They obtained balance either in the upper thermosphere above $265 \mathrm{~km}$ or in the lower thermosphere below $212 \mathrm{~km}$. For periods where the predicted temperature is too low compared with the measured one in our data set (e.g. Fig. 1, 18:4519:10 UT and 19:25-19:40 UT), the method of Sica et al. (1993) would give a balance at lower observing heights than we have determined from the electron density profile. Accordingly, instead of, or in addition to, the neglected heat sources in Eq. (1), the discrepancies could be explained by unforeseen behaviour of the peak emission height. However, there appears to be no evidence of any significant reduction in electron density peak height during 18:45-19:10 and 19:25-19:40 UT on 9 November, 1998. The dominance of frictional heating on ion temperature enhancements over the neutral temperature, particularly for active periods, would be found by both methods of height determination.

The vector plots in panel 2 of Figs. 1 and 2 show the F-region ion drift and neutral wind measurements perpendicular to the magnetic field. It is seen that the ion and neutral velocity vectors follow the same trend on the geomagnetically active day (Fig. 1). Generally, there is a much greater variability in the ion velocities than the neutral wind, which is consistent with satellite observations (e.g. Killeen et al., 1985, 1991). This results from the very much greater density of neutrals over ions. The primary force determining thermospheric circulation is ion-drag (Killeen and Roble, 1984) with the inertia of the neutrals smoothing out the highly variable ion velocities with a time constant of about $1-3 \mathrm{~h}$ (Killeen et al., 1984). The eastward and northward components of the electric field are shown in the fourth and fifth panels of Figs. 1 and 2. They are calculated both with (red curve) and without (black curve) the neutral wind contribution $\left(\mathbf{E}_{\text {eff }}=(\mathbf{u}-\mathbf{v}) \times \mathbf{B}\right)$. Neglecting the neutral wind generally has the effect of overestimating the effective electric field. After $\sim 21$ UT on 9 November, 1998, the neutral wind speed exceeds the ion drift magnitude, resulting from the flywheel effect
(Killeen and Roble, 1988). As the geomagnetic activity declines after 21 UT (Fig. 1, panel 8) the ion velocity correspondingly decreases. Now neutral inertial drag is acting on the ions, which is the reverse of the normal circumstance. As a result, especially the eastward electric field is driven by the dominant neutral wind and is even reversed in direction.

The sixth panel of Figs. 1 and 2 shows the local frictional or Joule heating rates $Q_{J \text {,eff }}$ and $Q_{J}$, calculated with (red curve) and without (black curve) the neutral wind contribution to the electric field, respectively, in the F-region. The heating rates are integrated over the ranges of $250-350 \mathrm{~km}$ and $200-300 \mathrm{~km}$ altitude for Figs. 1 and 2 , respectively. The integration ranges are selected with respect to the different $h_{m} \mathrm{~F} 2$ heights during both observation periods, corresponding to the height ranges shown in panel 3. It is seen that neglecting the neutral wind generally results in an overestimation of local Joule heating. On 10 November, 1998, most of the underestimation results from the fact that the ion drifts and neutral winds were generally very different in direction (see Fig. 2, panel 2) which leads to enhanced electric fields in accordance with $\mathbf{E}_{\text {eff }}=(\mathbf{u}-\mathbf{v}) \times \mathbf{B}$. Since the local Joule heating rate is proportional to $\mathbf{E}^{2}$ and $\sigma_{p}$ (or electron density $N_{e}$ ), the variation with time of the heating rate is somewhat different from that of the ionneutral temperature difference, which is density independent. The height-averaged Pedersen conductivity $\sigma_{p}$, calculated from EISCAT data, is shown in panel 7 of Figs. 1 and 2.

Figure 5 shows the distribution of percentage differences between $Q_{J \text {,eff }}$ and $Q_{J}$, separated for the magnetically active and quiet days. The total number of sampled values is the same as for Fig. 4. The distribution seems to be dependent on magnetic activity. During the active period (9 November), neglecting the neutral wind leads to an average error of about $60 \%$, with the effective ionneutral frictional heating rate being overestimated. In contrast, during the quiet period (10 November) the percentage differences are distributed over almost the full range between $\pm 100 \%$, forming no clear single maximum. Clearly, during both periods of observation presented here, the neutral wind is very important for both qualitative and quantitative considerations.

Kosch and Nielsen (1995) studied E-region statistically averaged Joule heating over Scandinavia using the STARE radar system and a Pedersen conductance model. STARE measures the ionospheric electric field at about $105 \mathrm{~km}$ altitude. They found that E-region Joule heating was essentially dependent on the square of the $K_{p}$ index. It is interesting to compare their results with the present study. For the active day of 9 November, $1998\left(K_{p}=5^{-}-7^{-}\right)$, the average expected E-region Joule heating ranges between 8.2 and $16.6 \mathrm{~mW} / \mathrm{m}^{2}$, which is greater than the F-region heating shown in panel 6 of Fig. 1 for any time. This result is not unexpected, since Pedersen conductivity maximises in the E-layer and Joule heating is proportional to this value. No comparison is made for the quiet day $\left(K_{p}=0^{+}-0\right)$ since STARE has very poor measurement statistics for $K_{p}<2$. 

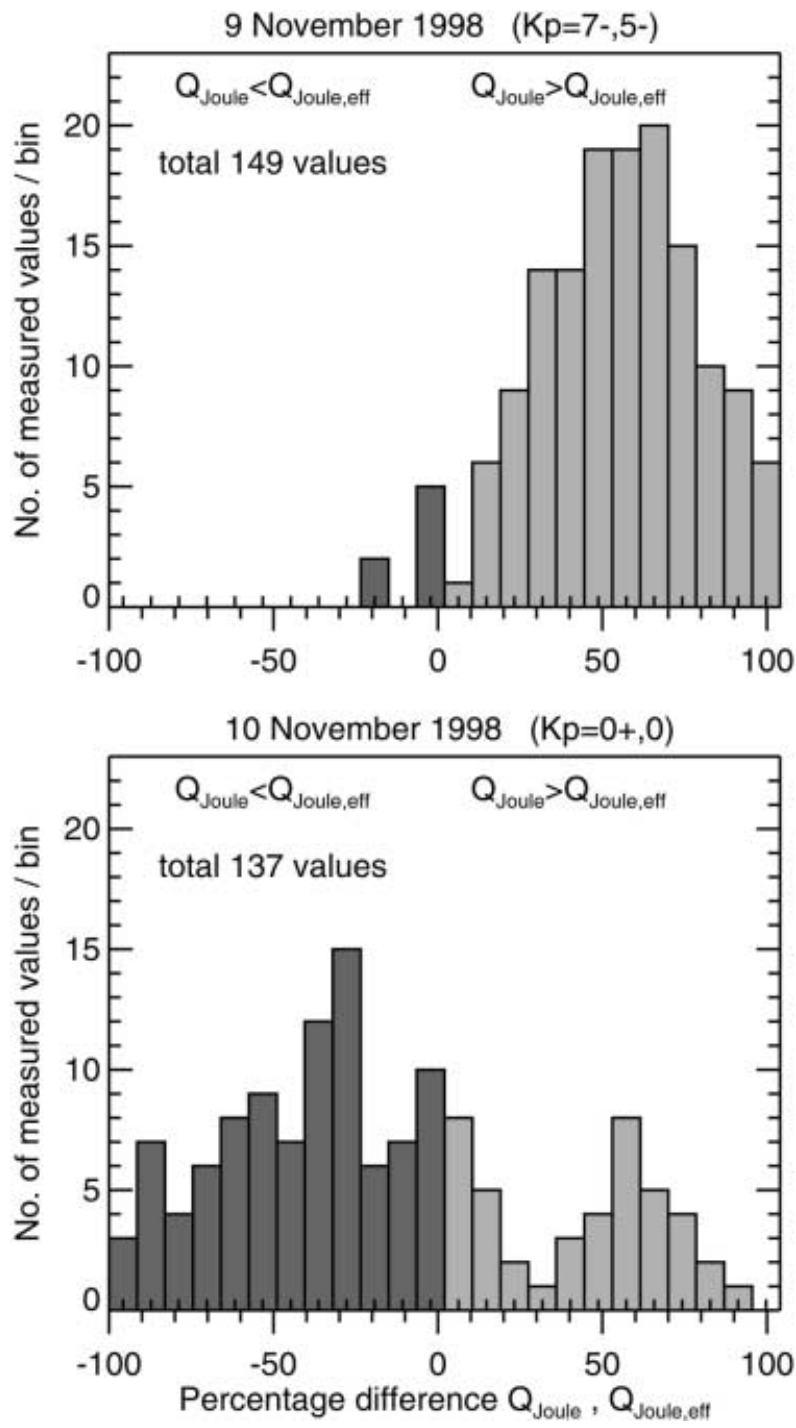

Fig. 5. Distributions of the percentage difference between the local Joule heating rates $Q_{\text {Joule,eff }}$ and $Q_{\text {Joule }}$ in the F-layer, calculated with and without the neutral wind contribution, respectively

It should be noted that, in the analysis of the raw EISCAT data, the standard fit was used which assumes that the ion population above $300 \mathrm{~km}$ consists of $100 \%$ $\mathrm{O}^{+}$and that the ion velocity distribution is Maxwellian. The validity of these assumptions decreases with increasing electric field strength (e.g. Lathuillere and Hubert, 1989). Given the small aspect angle in the case of the CP-1 experiment and that the ion-neutral differential velocities are lower than $1500 \mathrm{~m} / \mathrm{s}(\mathbf{E} \approx 75 \mathrm{mV} / \mathrm{m})$ in our observation periods, the distortion of the spectra in the magnetic field-aligned direction is expected to be small (e.g. Gaimard et al., 1996). Therefore, nonMaxwellian effects, except for the temperature anisotropy mentioned earlier, are not considered further here. However, for moderate electric fields greater than about $30 \mathrm{mV} / \mathrm{m}, \mathrm{NO}^{+}$is substantially increased in relation to $\mathrm{O}^{+}$in the F-layer (Schunk and Banks, 1976). The ion composition affects the derived ion and electron temperatures and to some extent the electron density, but not the ion velocity. Furthermore, the relative abundance of $\mathrm{N}_{2}$ with respect to $\mathrm{O}$ is increased from quiet to active conditions. The ion energy balance (Eqs. 1 and 2) depends directly on the neutral mass and is therefore strongly affected by neutral composition changes. The difficulties with composition uncertainties, particurlarly in the atomic to molecular transition region, are pointed out by St.-Maurice et al. (1999). Limiting their study to altitudes greater than $250 \mathrm{~km}$ or less than $170 \mathrm{~km}$ to avoid this problem, they use the standard EISCAT ion composition model. For the data presented here, electric fields exceeding $25 \mathrm{mV} / \mathrm{m}$ only occur on 9 November, 1998, when the observing height lies above $250 \mathrm{~km}$. Nevertheless, for the two short periods of this day, which are characterised by relatively high electric fields, the effects of composition changes on the comparison between measured and predicted ion temperature are estimated below.

During the intervals of 19:30-19:50 UT and 20:1020:40 UT on 9 November, 1998, the effective electric field peaked at values of about $60 \mathrm{mV} / \mathrm{m}$. First, the effects of ion composition changes are considered: in order to get an estimate of the expected reduction of the $\left[\mathrm{O}^{+}\right] / \mathrm{N}_{e}$ ratio, the results of Mikhailov and Schlegel (1998) are applied. From their calculation of the height variations of the ion composition for geomagnetically disturbed periods, we obtain the values $\left[\mathrm{O}^{+}\right] / \mathrm{N}_{e}=65 \%$ and $\left[\mathrm{O}^{+}\right] / \mathrm{N}_{e}=80 \%$ for a period with an average $\mathbf{E} \approx 85 \mathrm{mV} / \mathrm{m}$ and $\mathbf{E} \approx 35 \mathrm{mV} / \mathrm{m}$, respectively, at $300 \mathrm{~km}$ altitude. With the formulas given by Alcaydé et al. (1996), we calculate the range of the resulting correction factor for the EISCAT standard-fit ion temperature $T_{i}$, which gives an enhancement between $5.5 \% \quad(\mathbf{E}=35 \mathrm{mV} / \mathrm{m})$ and $12.3 \% \quad(\mathbf{E}=85 \mathrm{mV} / \mathrm{m})$. Secondly, the effects of neutral composition changes are considered: as mentioned above, the neutral mass in Eqs. (1) and (2) is obtained from the MSISE-90 model. For quiet periods, the MSISE-90 is in good agreement with the model calculations of Fuller-Rowell et al. (1991). During F-region storms $\left(K_{p}=6\right.$, which is comparable with the activity level on 9 November, 1998), their calculations for high-latitudes show an enhancement of the mean molecular mass from $\sim 19$ to $\sim 22.5 \mathrm{amu}$. Applying this correction for the intervals noted above, an enhancement of less than $10 \%$ of the predicted ion temperature occurs. As a result, if both ion and neutral composition corrections are applied during the intervals noted above, measured as well as predicted ion temperatures are higher compared with the standard calculations in Fig. 1, panel 1. However, the agreement between measurement and prediction is only slightly affected (the difference being less than 10\%). Hence, the effects of ion composition changes can be neglected for this case study since they are within our measurement uncertainty range.

\section{Concluding remarks}

A study of local F-layer ion-neutral frictional heating effects on ion temperature enhancements over neutral temperature, at high latitudes, has been undertaken 
using simultaneous measurements of ion velocity and temperature by EISCAT as well as neutral wind and temperature from a Fabry-Perot interferometer. A geomagnetically active period $\left(K_{p}=7^{-}-5^{-}\right)$and quiet period $\left(K_{p}=0^{+}-0\right)$ were studied. It is found that the neutral wind generally results in a reduction of the effective ionospheric electric field and resulting Joule or frictional heating. Neglecting the neutral wind can result in local frictional heating being overestimated by about $60 \pm 40 \%$ during an active period. During a quiet period there appears to be no clear trend in the percentage difference error estimate.

Ion-neutral frictional heating dominates F-layer ion temperature enhancements over the neutral temperature, accounting for about $96 \%$ of the increase on average. The MSISE-90 neutral atmosphere model makes a reasonable prediction of the neutral temperature for active conditions, but fails for quiet conditions when it predicts neutral temperatures exceeding the measured ion temperature by approximately $100 \mathrm{~K}$. For the two nights studied here, there appears to be no substantial evidence that the ion temperature is anisotropic in space for an $\mathrm{O}^{+}$dominated ionosphere even though the ionospheric electric field is large at times $(30<\mathrm{E}<60 \mathrm{mV} / \mathrm{m})$. The best fit between data and prediction occurs for $\beta_{\|}=2 / 3$, i.e. no correction for anisotropic effects.

Future investigations of simultaneous E- and F-region observations are planned by additionally using the FPI measurements of the oxygen $557.7 \mathrm{~nm}$ emission with EISCAT tristatic measurements alternating between the E- and F-layers.

Acknowledgements. EISCAT is an international scientific association supported by the research councils of Finland, France, Germany, Japan, Norway, Sweden and the United Kingdom. We thank the EISCAT director and staff for running the radar and providing the data.

Topical Editor M. Lester thanks J.-P. Saint-Maurice and S. Maeda for their help in evaluation this paper.

\section{References}

Ahn, B.-H., S.-I. Akasofu, and Y. Kamide, The Joule heat production rate and particle energy injection rate as a function of the geomagnetic indices AE and AL, J. Geophys. Res., 88, 6275-6287, 1983.

Akasofu, S.-I., Energy coupling between the solar wind and the magnetosphere, Space Sci. Rev., 28, 121-190, 1981.

Alcaydé, D., J. Fontanari, P.-L. Blelly, and C. Lathuillere, On the influence of ion composition in the $\mathrm{F}_{1}$-region on incoherent scatter spectra, Ann. Geophysicae, 14, 1526-1529, 1996.

Banks, P. M., J. C. Forster, and J. R. Doupnik, Chatanika radar observations relating to the latitudinal and local time variations of Joule heating, J. Geophys. Res., 86, 6869-6878, 1981.

Davis, C. J., A. D. Farmer, and A. Aruliah, An optimised method for calculating the $\mathrm{O}^{+}-\mathrm{O}$ collision parameter from aeronomical measurements, Ann. Geophysicae, 13, 541-550, 1995.

Farmer, A. D., K. J. Winser, A. Aruliah, and D. Rees, Ion-neutral dynamics: comparing Fabry-Perot measurements of neutral winds with those derived from radar observations, Adv. Space Res., 10(6), 281-286, 1990.

Fujii, R., S. Nozawa, N. Matuura, and A. Brekke, Study on neutral wind contribution to the electrodynamics in the polar iono- sphere using EISCAT CP-1 data, J. Geophys. Res., 103, 14 731$14739,1998$.

Fuller-Rowell, T. J., D. Rees, H. Rishbeth, A. G. Burns, T. L. Killeen, and R. G. Roble, Modelling of composition changes during F-region storms: a reassessment, J. Atmos. Terr. Phys., 53, 541-550, 1991.

Gaimard, P., C. Lathuillere, and D. Hubert, "Non-Maxwellian" studies in the auroral $F$ region: a new analysis of incoherent scatter spectra, J. Atmos. Terr. Phys., 58, 415-433, 1996.

Gaimard, P., J.-P. St.-Maurice, C. Lathuillere, and D. Hubert, On the improvement of analytical calculations of collisional auroral ion velocity distributions using recent Monte carlo results, J. Geophys. Res., 103, 4079-4095, 1998.

Hedin, A. E., Extension of the MSIS thermosphere model into the middle and lower atmosphere, J. Geophys. Res., 96, 1159-1172, 1991.

Herrero, F. A., and J. W. Meriwether Jr., 6300- $\AA$ airglow meridional intensity gradients, J. Geophys. Res., 85, 41914204, 1980.

Kelley, M. C., The Earth's ionosphere, Academic Press, San Diego, 34, 1989.

Killeen, T. L., and R. G. Roble, An analysis of the high-latitude thermosphere wind pattern calculated by a thermospheric general circulation model, 1. Momentum forcing, J. Geophys. Res., 89, 7509-7522, 1984.

Killeen, T. L., and R. G. Roble, Thermospheric dynamics: contributions from the first 5 years of the Dynamics Explorer Program, Rev. Geophys., 26, 329-367, 1988.

Killeen, T. L., P. B. Hays, G. R. Carigan, R. A. Heelis, W. B. Hanson, N. W. Spencer, and L. H. Brace, Ion-neutral coupling in the high-latitude $\mathrm{F}$ region: evaluation of ion heating terms from Dynamics Explorer 2, J. Geophys. Res., 89, 74957508, 1984.

Killeen, T. L., R. A. Heelis, P. B. Hays, N. W. Spencer, and W. B. Hanson, Neutral motions in the polar thermosphere for northward interplanetary magnetic field, Geophys. Res. Lett., 12, 159-162, 1985.

Killeen, T. L., F. G. McCormac, A. G. Burns, J. P. Thayer, R. M. Johnson, and R. J. Niciejewski, On the dynamics and composition of the high-latitude thermosphere, J. Atmos. Terr. Phys., 53, 797-815, 1991.

Kosch, M. J., and E. Nielsen, Coherent radar estimates of average high-latitude ionospheric Joule heating, J. Geophys. Res., 100, 12 201-12 215, 1995.

Kosch, M. J., T. Hagfors, and D. Rees, A new Fabry-Perot interferometer for atmospheric studies with the EISCAT incoherent backscatter radar, Adv. Space Sci., 20(6), 11331136, 1997a.

Kosch, M. J., A. Kohsiek, K. Schlegel, and T. Hagfors, A new Fabry-Perot interferometer experiment for neutral atmosphere studies in conjunction with the EISCAT incoherent-backscatter radar system, Tech. Rep. MPAE-T-010-97-20, Max-Planck Institut für Aeronomie, 1997b.

Kosch, M. J., M. Ishii, S. Nozawa, D. Rees, K. Cierpka, A. Kohsiek, K. Schlegel, R. Fujii, T. Hagfors, T. J. Fuller-Rowell, and C. Lathuillere, A comparison of thermospheric winds and temperatures from Fabry-Perot interferometer and EISCAT radar measurements with models, Adv. Space Res., 26(6), 979-984, 2000.

Lathuillere, C., and D. Hubert, Ion composition and ion temperature in periods of high electric fields from incoherent scatter observations, Ann. Geophysicae, 7, 285-296, 1989.

Lilensten, J., G. Thuillier, C. Lathuillere, W. Kofman, V. Fauliot, and M. Hersé, EISCAT-MICADO coodinated measurements of meridional wind, Ann. Geophysicae, 10, 603-618, 1992.

Lu, G., D. N. Baker, R. L. McPherron, C. J. Farrugia, D. Lummerzheim, J. M. Ruohoniemi, F. J. Rich, D. S. Evans, R. P. Lepping, M. Brittnacher, X. Li, R. Greenwald, G. Sofko, J. Villain, M. Lester, J. Thayer, T. Moretto, D. Milling, O. Troshichev, A. Zaitzev, V. Odintzov, G. Makarov, and K. Hayashi, Global energy deposition during the January 1997 
magnetic cloud event, J. Geophys. Res., 103, 11 685-11 694, 1998.

McCrea, I. W., M. Lester, T. R. Robinson, J.-P. St.-Maurice, N. M. Wade, and T. B. Jones, Derivation of the ion temperature partition coefficients from the study of ion frictional heating events, J. Geophys. Res., 98, 15 701-15 715, 1993.

Mikhailov, A., and K. Schlegel, Physical mechanism of strong negative storm effects in the daytime ionospheric F2 region observed with EISCAT, Ann. Geophysicae, 16, 602-608, 1998.

Rees, D., N. Lloyd, P. J. Charleton, M. Carlson, J. Murdin, and I. Häggström, Comparison of plasma flow and thermospheric circulation over northern Scandinavia using EISCAT and a Fabry-Perot interferometer, J. Atmos. Terr. Phys., 46, 545-564, 1984.

Rishbeth, H., and A. P. van Eyken, EISCAT: early history and the first ten years of operation, J. Atmos. Terr. Phys., 55, 525-542, 1993.

Schlegel, K., and P. N. Collis, The storm of 10 January 1997: electrodynamics of the high latitude $\mathrm{E}$ region from EISCAT data, J. Atmos. Sol.-Terr. Phys., 61, 217-222, 1999.

Schunk, R. W., Mathematical structure of transport equations for multispecies flows, Rev. Geophys. Space. Phys., 15, 429-445, 1977.

Schunk, R. W., and P. M. Banks, Effects of electric fields and other processes upon the nighttime high-latitude F layer, J. Geophys. Res., 81, 3271-3282, 1976.

Schunk, R. W., and J. C. G. Walker, Theoretical ion densities in the lower ionosphere, Planet. Space. Sci., 21, 1875-1896, 1973.
Sica, R. J., J.-P. St.-Maurice, G. Hernandez, G. J. Romick, and Tsunoda, Computations of local ion energy balance in the auroral zone, J. Geophys. Res., 98, 15 667-15 676, 1993.

St.-Maurice, J.-P., and R. W. Schunk, Auroral ion velocity distributions for a polarisation collision model, Planet. Space. Sci., 25, 243-260, 1977.

St.-Maurice, J.-P., and R. W. Schunk, Ion velocity distributions in the high-latitude ionosphere, Rev. Geophys. Res., 17, 99-134, 1979.

St.-Maurice, J.-P., and W. B. Hanson, Ion frictional heating at high latitudes and its possible use for an in situ determination of neutral thermospheric winds and temperatures, J. Geophys. Res., 87, 7580-7602, 1982.

St.-Maurice, J.-P., C. Cussenot, and W. Kofman, On the usefulness of $\mathrm{E}$ region electron temperatures and lower $\mathrm{F}$ region ion temperatures for the extraction of thermospheric parameters: a case study, Ann. Geophysicae, 17, 1182-1198, 1999.

Thuillier, G., C. Lathuillere, M. Hersé, C. Senior, W. Kofman, M. L. Duboin, D. Alcaydé, F. Barlier, and J. Fontanari, Coordinated EISCAT-MICADO interferometer measurements of neutral winds and temperatures in the E- and F-regions, J. Atmos. Terr. Phys., 52, 625-636, 1990.

Troshichev, O. A., V. G. Andrezen, S. Vennerstrøm, and E. FriisChristensen, Magnetic activity in the polar cap - a new index, Planet. Space Sci., 36, 1095-1102, 1988.

Winser, K. J., A. D. Farmer, D. Rees, and A. Aruliah, Ion-neutral dynamics in the high-latitude ionosphere: first results from the INDI experiment, J. Atmos. Terr. Phys., 50, 369-377, 1988. 